\title{
Development of a single resistance to damage metric for mosquito nets related to physical integrity in the field
}

\author{
Amy Wheldrake ${ }^{1}$, Estelle Guillemois ${ }^{1}$, Vera Chetty ${ }^{1}$, Albert Kilian² ${ }^{2}$ and Stephen J. Russell ${ }^{*}$
}

\begin{abstract}
Background: In common with the majority of personal protective equipment and healthcare products, the ability for long-lasting insecticidal nets (LLINS) to remain in good physical condition during use is a key factor governing fitness for purpose and serviceability. The inherent ability of a product to resist physical deterioration should be known in advance of it being used to ensure it has maximum value to both the end-user and procurer. The objective of this study was to develop a single performance metric of resistance to damage (RD) that can be applied to any LLIN product prior to distribution.

Methods: Algorithms to calculate RD values were developed based on consideration of both human factors and laboratory testing data. Quantitative reference forces applied to LLINs by users during normal use were determined so that aspirational performance levels could be established. The ability of LLINs to resist mechanical damage was assessed based on a new suite of textile tests, reflecting actual mechanisms of physical deterioration during normal household use. These tests quantified the snag strength, bursting strength, abrasion resistance and resistance to hole enlargement. Sixteen different unused LLINs were included in the analysis. The calculated RD values for all LLINs and the corresponding physical integrity data for the same nets retrieved from the field (up to 3 years of use) were then compared.
\end{abstract}

Results: On a RD scale of 0 (lowest resistance) - 100 (highest resistance), only six of the sixteen LLINs achieved an RD value above 50. No current LLIN achieved the aspirational level of resistance to damage $(R D=100)$, suggesting that product innovation is urgently required to increase the RD of LLINs. LLINs with higher RD values were associated with lower hole damage (PHI) in the field when adjusted for normal use conditions.

Conclusions: The RD value of any LLIN product can be determined prior to distribution based on the developed algorithms and laboratory textile testing data. Generally, LLINs need to achieve higher RD values to improve their ability to resist hole formation during normal use. Innovation in LLIN product design focused on the textile material should be actively encouraged and is urgently needed to close the performance gap.

Keywords: Long-lasting insecticidal mosquito nets, Resistance to damage, Physical integrity, Durability

*Correspondence: stephenr@nonwovens-innovation.com

${ }^{1}$ Nonwovens Innovation \& Research Institute Ltd, 169 Meanwood Road, Leeds LS7 1SR, West Yorkshire, UK

Full list of author information is available at the end of the article

\begin{abstract}
Background
In terms of reliability engineering, long-lasting insecticidal nets (LLINs) should be capable of functioning under field conditions for 3 or more years, and resist failure during normal use by remaining in good physical condition [1]. However, it is well known that the actual service life of LLINs can fall markedly short of 3 years,
\end{abstract}


depending on prevailing circumstances. Whilst there have been numerous long-term studies monitoring the physical integrity and durability of LLINs using various methodologies [2-8], much less attention has been paid to the design of the LLIN product itself, and the inherent ability of products to resist damage. Therefore, at present, there is no single metric that reliably defines the inherent resistance to damage of a new LLIN before it is used.

Based on detailed laboratory analyses of used LLINs [9], distinct mechanisms of structural damage take place in LLINs that are common across different geographic regions and brands. Mechanical damage is the primary contributor to LLIN deterioration in normal use, both in terms of hole frequency and area. Of these mechanical damage mechanisms, snagging is responsible for the initiation of the largest proportion of holes. Although such holes may be initially small in dimensions, they can potentially enlarge to form significantly larger holes over time. Collectively, tearing, abrasion and seam failure are also responsible for a large proportion of the hole area, and their underlying mechanisms of damage would be practically difficult to avoid during normal use of a LLIN product. Tears usually form as a result of the net first being snagged on a solid object, such as wooden mattress material, and then when force is applied to pull it free, a tear is created. Abrasion occurs when two surfaces are rubbed against each other e.g. during washing or when the LLINs are tucked between the mattress and bedframe. Furthermore, forms of mechanical damage are recurrent across different geographical settings and are found in all knitted LLINs regardless of whether they are made of polyester (PET) or polyethylene (PE) $[10,11]$.

Studies have subsequently focused on developing textile testing methods for LLINs that relate to the actual damage sustained in the field [12]. Test method selection was based on identifying suitable test methods that accurately reflect the physical damage observed in LLINs analysed after use in the field [13]. Overall, four textile test methods based on existing or slightly modified ISO standards, have been proposed for LLINs to reflect actual modes of damage observed in the field. One of the proposed methods, i.e. the bursting test, is already used in the specification of LLIN products [14]. The other three methods are snag strength, hole enlargement and abrasion resistance [12]. This suite of four laboratory textile test methods currently yields four separate quantitative values to represent the inherent resistance to damage of LLINs.

The aim of the present study was to develop a single quantitative metric to define the resistance to damage (RD) of a LLIN based on the same laboratory test data, but which also considered the question how strong is strong enough?'. This formed the basis to develop a new algorithm for calculating RD for new LLINs that should assist with future innovation and the development of better performing products.

\section{Methods \\ Establishing real-life forces}

Over the course of normal use, LLINs accumulate physical damage that produce holes. For example, LLINs are frequently snagged on rigid objects, such as bits of wood, and when pulled by the user to free the snag, a force is generated. Little is known about the magnitude of the forces that are generated in such practical circumstances, and the levels required to induce filament breakages or create a tear. Simply stated, if the force measured in the lab under simulated conditions is greater than what can be normally generated by a human being in the field, then the LLIN can be expected to resist the accumulation of damage.

Such human factors and associated real-life forces and mechanisms of damage are routinely considered in the development of other protective and healthcare products to ensure products are fit for purpose. Table 1 indicates the maximum isometric forces that are capable of being safely exerted by a person [15]. According to this standard, a person in a seated position exerting a one-handed arm only pulling movement in a downwards direction, produces a maximum isometric force of $75 \mathrm{~N}$. These values relate to isometric forces that can be steadily exerted while the limbs are in a stationary position [16]. Under field conditions, forces will also occur as a result of explosive strength, i.e. a dynamic burst of movement, and in these instances the forces capable of being exerted by a user are likely to be higher [15].

The maximum explosive forces that can be generated by humans have been studied by other researchers with the aim of informing designers about the safe design of products [17]. Pulling strength was one of the aspects studied and the values obtained are shown in Table 2 . Note that the forces generated are much higher than those obtained for a person in a stationary position.

The mean weight of adult males taking part in the experiment was $80 \mathrm{~kg}$, while that for the women was $68 \mathrm{~kg}$. This is higher than the average weight of adults in malaria endemic countries (Table 3) [18]. Strength has long been established as being influenced, by body weight as well as other factors [19]. Therefore, this should be reflected when setting an aspirational performance target for the strength or resistance to damage of a LLIN based on published real life forces. Forces recorded in Newtons $(\mathrm{N})$ are straightforward to relate to the snag strength test in the laboratory, which measures the force $(\mathrm{N})$ required to break a yarn in the LLIN. Furthermore, data on the 
Table 1 Maximal isometric force measurements from EN 1005-3:2002 Safety of machinery [15]

\begin{tabular}{|c|c|c|c|}
\hline \multicolumn{2}{|l|}{ Activity } & \multirow{2}{*}{$\begin{array}{l}\text { Professional use } \\
F_{a} \text { in } N \\
250\end{array}$} & \multirow{2}{*}{$\begin{array}{l}\text { Domestic use } \\
\mathbf{F}_{\mathrm{a}} \text { in } \mathbf{N} \\
184\end{array}$} \\
\hline & $\begin{array}{l}\text { Hand work (one hand): } \\
\text { power grip }\end{array}$ & & \\
\hline & Arm work (sitting posture, one arm): & & \\
\hline & upwards & 50 & 31 \\
\hline & downwards & 75 & 44 \\
\hline & outwards & 55 & 31 \\
\hline & inwards & 75 & 49 \\
\hline & pushing: & & \\
\hline & with trunk support & 275 & 186 \\
\hline & without trunk support & 62 & 30 \\
\hline & pulling: & & \\
\hline & with trunk support & 225 & 169 \\
\hline & without trunk support & 55 & 28 \\
\hline
\end{tabular}

Table 2 Minimum and maximum mean force for overhand and underhand explosive

$\begin{array}{ll}\text { Male aged 21-60 } & \text { Female } \\ \text { Min-Max mean force } & \text { aged 21-60 } \\ \text { (N) } & \text { Min-Max }\end{array}$

mean force

(N)

\begin{tabular}{lll}
\hline Underhand pulling & $145-185$ & $85-123$ \\
Overhand pulling & $99-308$ & $78-260$ \\
\hline
\end{tabular}

Table 3 Mean body weight of adult humans in different malaria-endemic countries

\begin{tabular}{ll}
\hline Mean weight of adult human & \\
\hline Country & kg \\
\hline India & 52.9 \\
Ethiopia & 53.1 \\
Congo & 53.5 \\
Cambodia & 55.7 \\
Mozambique & 56 \\
Kenya & 56.3 \\
Uganda & 57 \\
Benin & 60.3 \\
Nigeria & 60.7 \\
All of World & 62 \\
\hline
\end{tabular}

forces generated during underhand or overhand pulling is available (Fig. 1) [17].

\section{LLIN samples for testing}

Sixteen different new and unused LLIN products supplied by 10 different brands representing the majority of WHOPES (World Health Organization Pesticide Evaluation Scheme) recommended insecticide treated nets (ITNs) in 2013 were obtained from suppliers to allow textile testing data to be generated for snag strength, bursting strength, abrasion resistance and hole enlargement. Details of the sample preparation, textile testing procedures and number of replicates have been previously reported [12]. The datasets for each LLIN were then used to calculate a RD value based on the developed algorithm.

\section{Algorithm development}

Approaches for predicting the service life of products, product performance during use, and warranty costs $[20,21]$ are all well established. Methods to predict service life of products rely on mathematical models based on prior knowledge of the appropriate distribution that should be used, as well as data on how users and the environment interact with products in the field [22]. Given the complexities involved in such an approach with LLINs, a criterion-referenced assessment of the resistance to damage of LLINs was applied based upon the quantitative values obtained for each durability test 

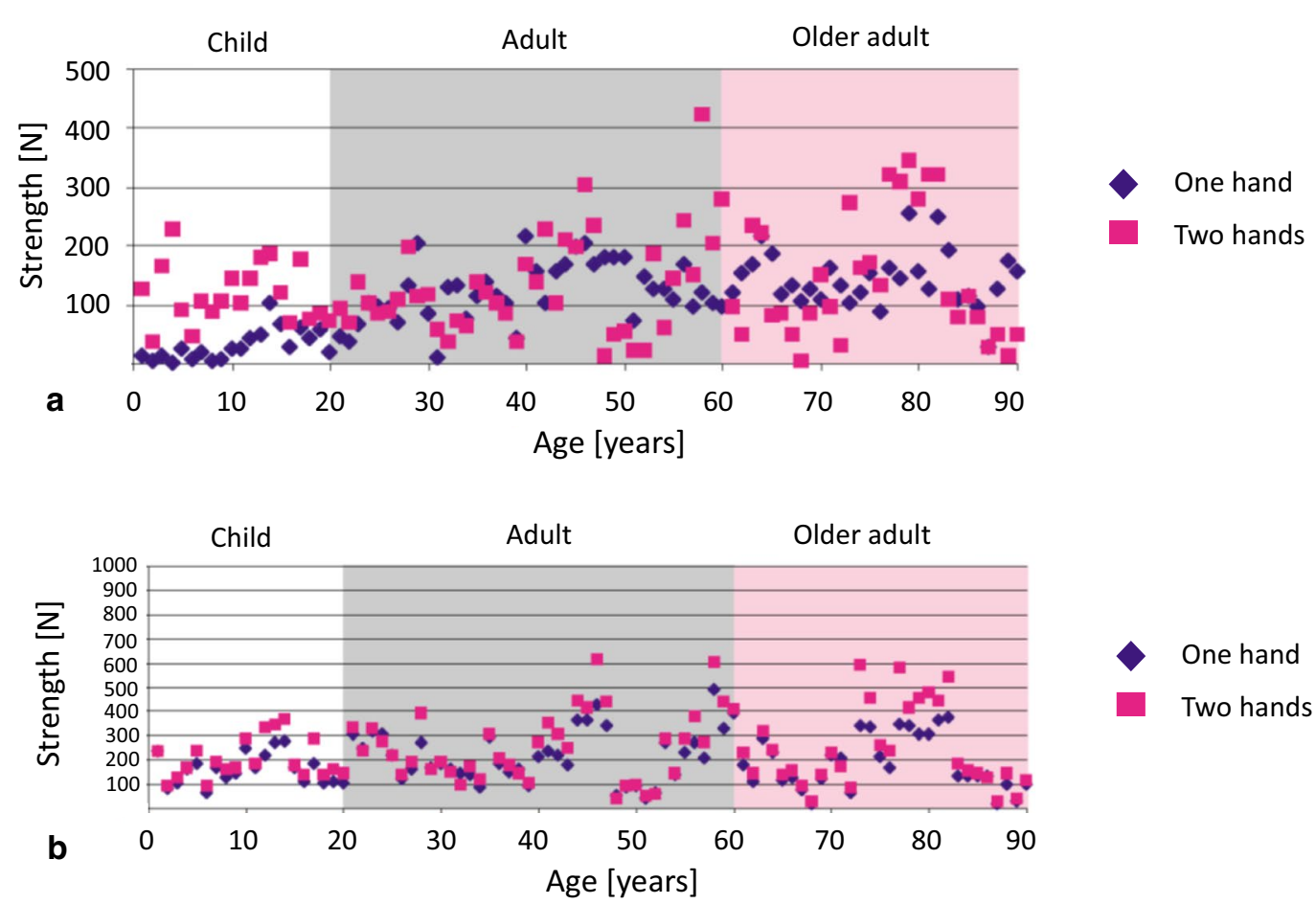

One hand

Two hands

Fig. 1 Maximum pulling strength a using an underhand grip and $\mathbf{b}$ on a round handle using an overhand grip [17]

parameter and human factors, specifically based on the magnitude of forces that is likely to be applied to a LLIN by its user. Two different methods were developed for determining the RD values for LLINs.

Method 1: Proximity to aspirational values In this method, laboratory testing data for snag strength, bursting strength, abrasion and hole enlargement, i.e. actual values $(\lambda)$, were compared with aspirational values $(n)$ for each parameter to determine numerical differences in performance. The mean value for each parameter was then divided by four so that each contributed equally to the overall RD value, expressed as a percentage (Eq. 1):

$$
\mathrm{RD}=\left(\frac{\lambda_{B}}{\eta_{B}} \times \frac{100}{4}\right)+\left(\frac{\lambda_{S}}{\eta_{S}} \times \frac{100}{4}\right)+\left(\frac{\lambda_{A}}{\eta_{A}} \times \frac{100}{4}\right)+\frac{\sigma_{H}}{4}
$$

where: $\mathrm{RD}=$ Resistance to damage; $\lambda_{B}=$ Actual bursting strength $(\mathrm{kPa}) ; \eta_{B}=$ Aspirational bursting strength $(\mathrm{kPa}) ; \lambda_{S}=$ Actual snag strength $(\mathrm{N}) ; \eta_{S}=$ Aspirational snag strength $(\mathrm{N}) ; \lambda_{A}=$ Actual abrasion resistance strength (number of rubs); $\eta_{A}=$ Aspirational abrasion resistance (number of rubs); $\sigma_{\mathrm{H}}=$ Hole enlargement resistance score.

The hole enlargement value for Eq. 1 was defined by a score, which was based on the final hole size obtained in the hole enlargement laboratory test and the presence (or not) of hole enlargement due to laddering, unravelling or tearing, as defined in Table 4.

\section{Algorithm development-method 2: proximity to aspirational value by $\mathrm{KPI}$}

Method 2 is based on a Key Performance Indicator system (KPI), which uses the laboratory data to establish scores for each of the four individual test parameters. The basic approach is used across a range of sectors including healthcare, performance monitoring in the business sector, education and customer services [23, 24]. As the name suggests, the method measures performance against pre-specified criteria based on aspirational values

\begin{tabular}{|c|c|c|c|}
\hline \multirow[t]{2}{*}{ Damage type } & \multicolumn{3}{|c|}{ End hole size } \\
\hline & $<5 \mathrm{~mm}$ & $6-20 \mathrm{~mm}$ & $\geq 21 \mathrm{~mm}$ \\
\hline None & 100 & 80 & 40 \\
\hline Laddering & 80 & 64 & 32 \\
\hline Unravelling & 50 & 40 & 20 \\
\hline $\begin{array}{l}\text { Tearing combined } \\
\text { with laddering or } \\
\text { unravelling }\end{array}$ & 40 & 32 & 16 \\
\hline
\end{tabular}


defined for each test parameter. The methodology allows for qualitative data to be included and provides a solution for dealing with multi-objective outcomes. It does this by use of a scoring matrix. The score matrix structure is illustrated in Table 5. For each test parameter, the matrix defines test value ranges up to the aspirational value in equal proportions. The overall score for bursting strength, snag strength, abrasion resistance and hole enlargement contribute equally to the overall RD value.

For the hole enlargement resistance score, a weighting is applied, as indicated in Table 4, which is based on the hole enlargement behaviour. These weightings are based on the analysis of field nets in the study by Wheldrake et al. [13], where laddering, unravelling and tearing were responsible for large holes, and as such their presence results in large weightings. In method 2, the overall RD value is, therefore, calculated as follows (Eq. 2).

$$
R D=\sigma_{B}+\sigma_{S}+\sigma_{A}+\left(\sigma_{H}-\rho_{H}\right)
$$

where $\sigma_{B}$ is the score for bursting strength, $\sigma_{S}$ is the score for snag strength, $\sigma_{A}$ is the score for abrasion resistance, $\sigma_{H}$ is the score for hole enlargement resistance and $\rho_{H}$ is the penalty score.

\section{Correlation}

The calculated RD values for all LLINs were determined based on the laboratory test data obtained from the suite of four textile tests [12] and the two methodological approaches (Methods 1 and 2) using equations 1 and 2. To explore any correlation between the RD data obtained in the lab and the extent of hole formation in the field, $R D$ values for different LLINs were compared with previously reported [13] proportionate hole index (PHI) data after 1-3 years which uses the World Health Organization (WHO)-recommended metric for physical integrity in the field [25]. The proportionate hole index (PHI) data corresponds exclusively to holes that through forensic assessment were determined to have been the result of mechanical damage from reasonable household use, i.e. snagging, tearing and abrasion, and excluding cut, seam failure, rodent and thermal damage. The PHI for each LLIN was calculated following WHO guidelines as summarized in Table 6.

Thus, if the weighting of the hole sizes 1, 2, 3 and 4 is $\alpha$, $\beta, \gamma$ and $\delta$ respectively, the hole index $\left(\mathrm{H}_{\mathrm{i}}\right)$ is calculated as in Eq. 3:

$$
\mathrm{H}_{i}=\left(\alpha \times \mathrm{N}_{1}\right)+\left(\beta \times \mathrm{N}_{2}\right)+\left(\gamma \times \mathrm{N}_{3}\right)+\left(\delta \times \mathrm{N}_{4}\right)
$$

where $\mathrm{N}_{1}$ is the number of size 1 holes, $\mathrm{N}_{2}$ is the number of size 2 holes, $N_{3}$ is the number of size 3 holes and $N_{4}$ is the number of size 4 holes.

\section{Results \\ Specification of aspirational values \\ Snag strength}

The laboratory snag test is performed over a small surface area of the fabric $\sim 1 \mathrm{~mm}^{2}$ [12], which is consistent with the relatively small holes that this mechanism most frequently produces in real field nets [13]. The maximum explosive force a male of 21-60 years weighing an average of $80 \mathrm{~kg}$ can exert in an overhand pulling motion is reported to be $308 \mathrm{~N}$ [17] and therefore it is unlikely that a LLIN with snag strength of $>300 \mathrm{~N}$ would be readily damaged by snagging during normal use. Based on the results in Fig. 1, if a maximum upper limit, or effective reference value, was therefore placed at $200 \mathrm{~N}$ it would be greater than the maximum most of the expected users in malaria-endemic regions could exert on the LLIN in an underhand grip (Fig. 1a). In the case of overhand pulling (Fig. 1b), a proportion of the measured forces occur above $200 \mathrm{~N}$, but it should be noted that this data set is based on a heavier adult population. Additionally, to verify the ease with which yarns in LLINs could be broken by human adults, manual snag tests were performed with a mixture of males and females aged between 27 and 42 years and weighing between 58 and $90 \mathrm{~kg}$. LLINs with snag strength greater than $60 \mathrm{~N}$ required substantial effort by the participants to break the filaments. Thus, $200 \mathrm{~N}$ is considered a reasonable aspirational snag strength value.

\section{Bursting strength}

In Table 2, the mean maximum overhand pulling force that can be generated by an adult male aged 21-60 years is $308 \mathrm{~N}$. Considering the $7.3 \mathrm{~cm}^{2}$ burst area, this is equivalent to $421 \mathrm{kPa}$. Therefore, in theory, a LLIN with a bursting strength $>421 \mathrm{kPa}$ caught on a $7.3 \mathrm{~cm}^{2}$ surface and pulled with an underhand grip in an explosive manner, by a $21-60$ years old adult male weighing $\leq 80 \mathrm{~kg}$, should not easily break. This is based on assumptions such as the pressure being equally distributed across the surface area. In reality, LLINs with bursting strengths $>421 \mathrm{kPa}$ have been found to contain tears [13]. This is likely to be due to nets being caught on smaller radius objects, which reduce the surface area over which the force acts. For example, if the same $308 \mathrm{~N}$ force was exerted over half the surface area of $3.65 \mathrm{~cm}^{2}$, the equivalent pressure would be $843 \mathrm{kPa}$. If the surface area was reduced further to represent a corner of a bed frame, e.g. $1 \mathrm{~cm}^{2}$ surface area, the equivalent pressure would increase to $>3000 \mathrm{kPa}$.

If the upper limit for force based on reasonable use is ca. $200 \mathrm{~N}$ [26] and this is applied to bursting strength using a $7.3 \mathrm{~cm}^{2}$ burst area, the corresponding pressure at break is $274 \mathrm{kPa}$. This is similar to the current WHO 


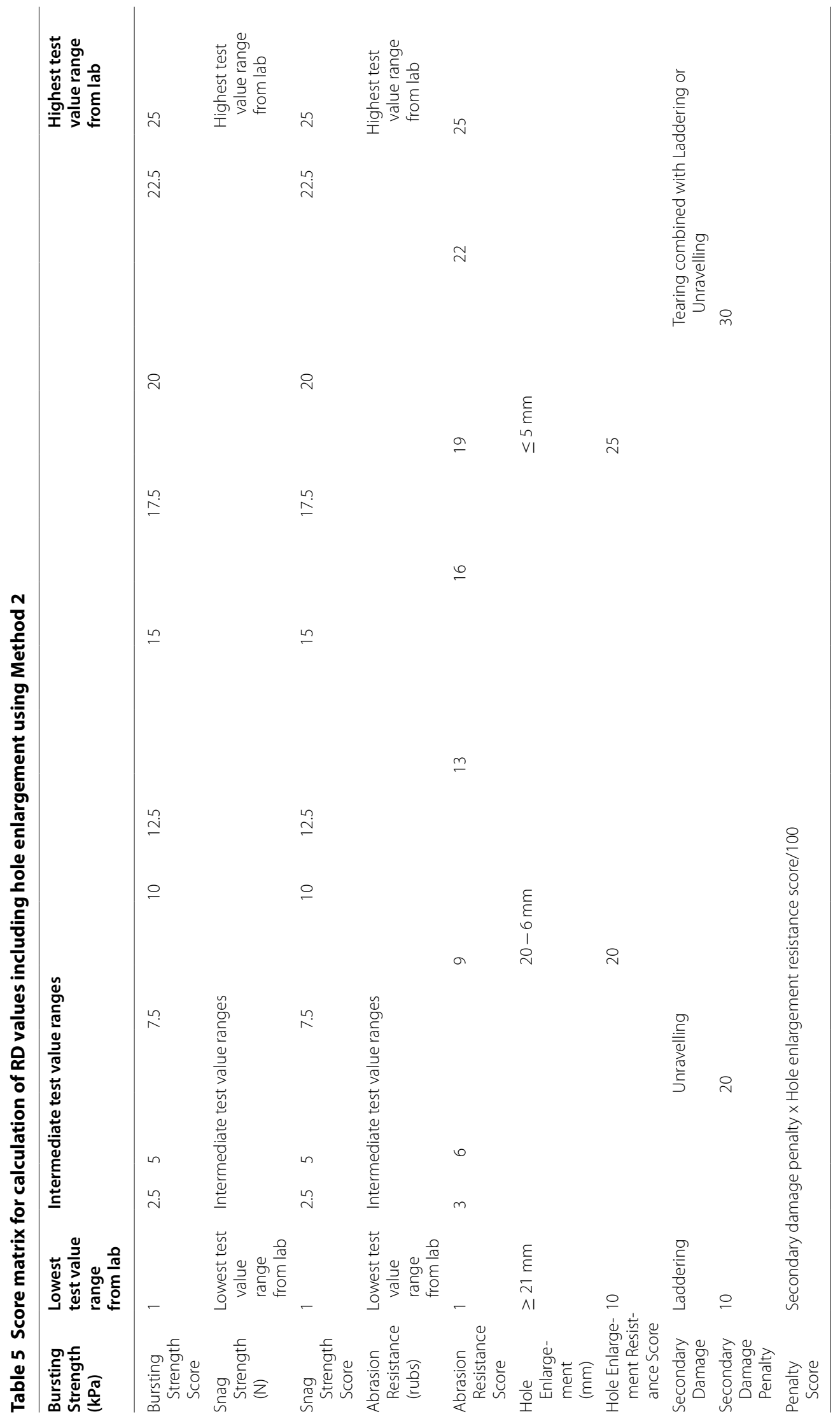


Table 6 WHO hole size guidelines and hole index used to assess physical integrity of LLINs

\begin{tabular}{|c|c|c|c|c|c|c|}
\hline \multirow[t]{2}{*}{ WHO 2013 guidelines } & \multirow{2}{*}{$\begin{array}{l}\text { Size banding } \\
\mathrm{cm}\end{array}$} & \multirow{2}{*}{$\begin{array}{l}\text { Hole diameter } \\
\mathrm{d} ; \mathrm{cm}\end{array}$} & \multicolumn{2}{|l|}{ Hole radius } & \multirow{2}{*}{$\begin{array}{l}\text { Area of hole } \\
\mathrm{cm}^{2}\end{array}$} & \multirow[t]{2}{*}{ Hole Index ${ }^{a}$} \\
\hline & & & $\mathrm{r}=\mathrm{d} / 2 ; \mathrm{cm}$ & $\mathrm{r}^{2} ; \mathrm{cm}^{2}$ & & \\
\hline $\begin{array}{l}\text { Size } 1 \\
\text { Smaller than a thumb }\end{array}$ & $0.5-2$ & 1.25 & 0.625 & 0.3906 & 1.23 & 1 \\
\hline $\begin{array}{l}\text { Size } 2 \\
\text { Larger than a thumb but smaller than a fist }\end{array}$ & $2.5-10$ & 6 & 3 & 9 & 28.28 & 23 \\
\hline $\begin{array}{l}\text { Size } 3 \\
\text { Larger than a fist but smaller than a head }\end{array}$ & $11-25$ & 17.5 & 8.75 & 76.5625 & 240.56 & 196 \\
\hline $\begin{array}{l}\text { Size } 4 \\
\text { Larger than a head }\end{array}$ & $\geq 26$ & $30^{b}$ & 15 & 225 & 706.95 & 576 \\
\hline
\end{tabular}

$\mathrm{A}$-area of the hole $\mathrm{pr}^{2} ; \mathrm{p}=3.142 ;{ }^{\mathrm{a}}$ Area divided by $1.23 ;{ }^{\mathrm{b}}$ Assumer diameter

threshold value of $250 \mathrm{kPa}$ [27]. However, the possibility of the surface area in the field being substantially smaller than $7.3 \mathrm{~cm}^{2}$ also needs to be taken into account, and, therefore, a safety factor needs to be built in. It is not possible to predict the possible surface areas that the net will interact with, which may lead to a failure, as these will be greatly variable in size, shape and surface texture. Generally, forces greater than $500 \mathrm{~N}$ would be at the upper limit of what is likely to be generated, which over a $7.3 \mathrm{~cm}^{2}$ area is equivalent to $685 \mathrm{kPa}$. Therefore, the aspirational level for the bursting strength of the nets was estimated at $\geq 700 \mathrm{kPa}$. Note that current burst testing equipment used by most textile testing laboratories record values up to a maximum of $1000 \mathrm{kPa}$.

\section{Abrasion resistance}

Other industries that use an accelerated abrasion test with fine sandpaper as the abradant set a pass rate at 1000 rubs [28]. However, this is usually based on testing heavier-weight woven fabrics that are subjected to intensive flat abrasion during use. Therefore, based on the proportional difference in weight and in the mode of use of LLINs, an aspirational reference value of 400 rubs without failure was estimated.

\section{Hole enlargement}

Current WHO guidelines recommend that hole sizes of $5 \mathrm{~mm}$ and greater are recorded [29]. This size is considered to be of practical relevance, given that the principal role of a LLIN is to act as a physical barrier to the penetration of mosquitoes. Therefore, it is consistent with current WHO guidelines to suggest an aspirational hole enlargement size of $5 \mathrm{~mm}$ following a yarn breakage, which is equivalent to a score of 100 for hole enlargement.

In the Proportionate Hole Index (PHI) used to determine the condition of field nets, size 1 holes are those between 5 and $20 \mathrm{~mm}$. Herein, a penalty weighting was therefore introduced because of the need to account for LLINs that are susceptible to hole enlargement once yarns in the fabric are broken as a consequence of their knitting pattern. The hole enlargement resistance score due to secondary tears, laddering and unravelling are also accounted for in the RD calculation. The most serious secondary damage in terms of the size of holes formed is associated with combination of laddering and tearing or unravelling and tearing and this is reflected in the suggested weightings.

A summary of the aspirational values for each parameter comprising the RD value and used to calculate RD by method 1 and 2 (Eqs. 1 and 2) is given in Tables 7 and 8.

The RD values for each LLIN calculated using Method 1 (Proximity to Aspirational Values) are reported in Fig. 2. Marked differences in RD values were observed across the different LLIN products, and none reached the aspirational value $(\mathrm{RD}=100)$. Six LLINs achieved

Table 7 Definition of effective reference values for snag strength, bursting strength abrasion resistance and hole enlargement

\begin{tabular}{lllll}
\hline & \multicolumn{2}{l}{ Textile Testing Parameter } & & \\
\cline { 2 - 5 } & Mean snag strength (N) & Mean bursting strength $\mathbf{( k P a )}$ & $\begin{array}{l}\text { Abrasion resistance (number } \\
\text { of rubs) }\end{array}$ & $\begin{array}{l}\text { Hole enlargement resistance } \\
\text { score }\end{array}$ \\
\hline Aspirational value $\geq 200$ & $\geq 700$ & 400 (Allows 5 out of 15 to fail) & $\begin{array}{c}100 \text { No Laddering No Unravel- } \\
\text { ling No Tearing }\end{array}$ \\
\hline
\end{tabular}




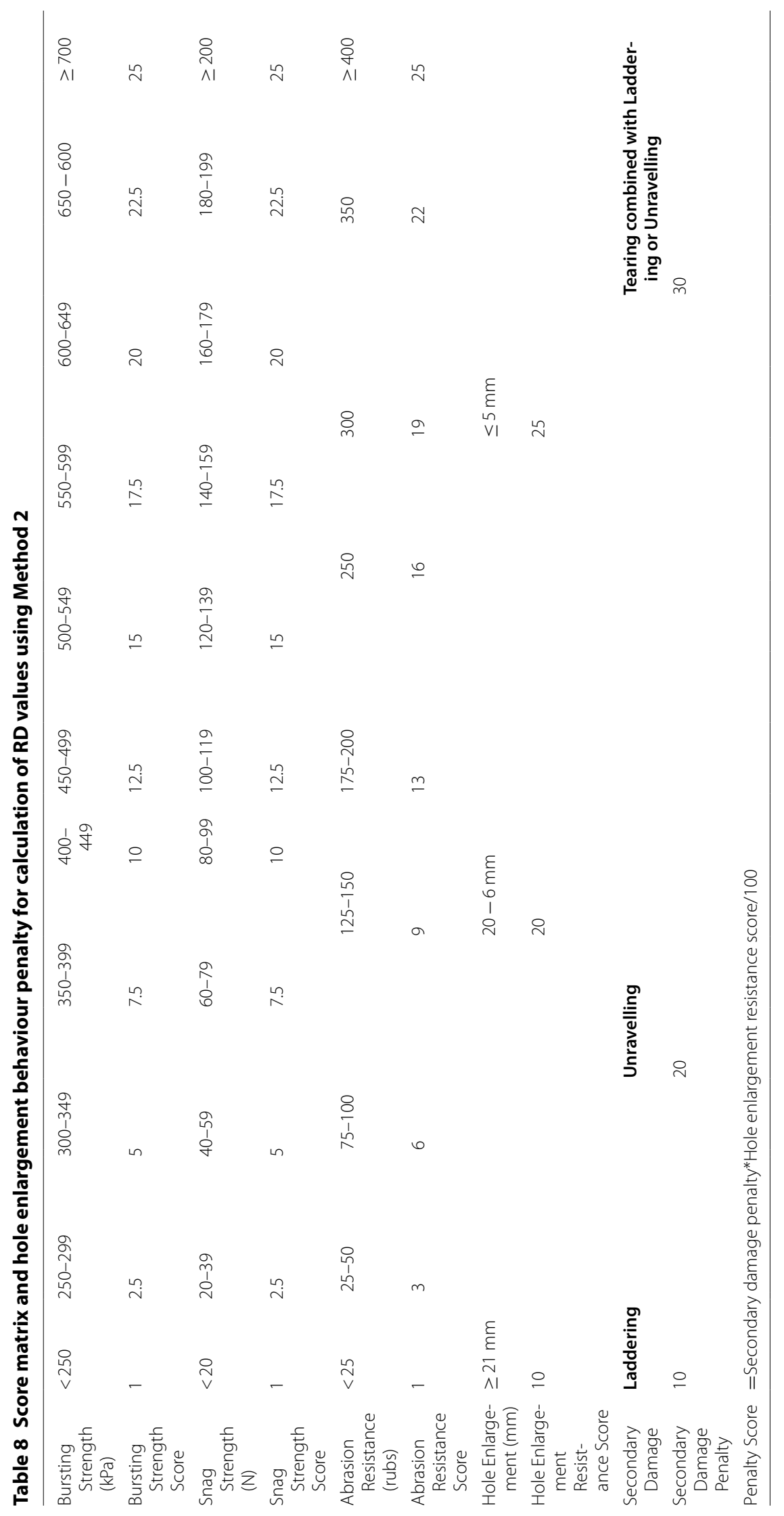




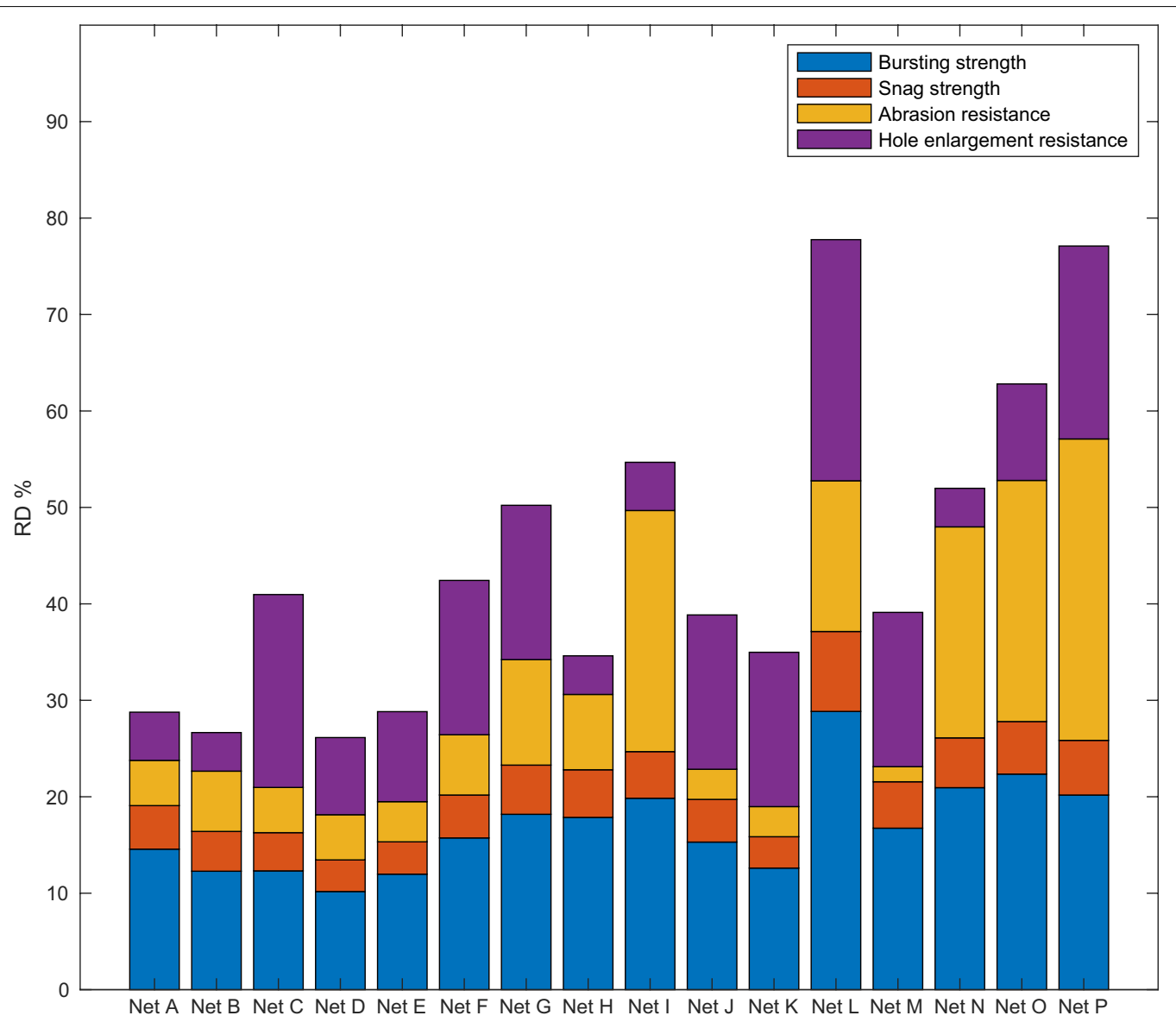

Fig. 2 RD values for all LLINs following algorithm Method 1

RD values of $50 \%$ RD (Net G, I, L, N, O and P), the remaining ten LLINs produced $R D$ values of $<50$.

These data also highlight marked differences in the performance of LLIN products in relation to each of the four damage mechanisms. The high resistance to abrasion of Net P and hole enlargement resistance in Net $\mathrm{L}$ are particularly noteworthy. The RD data (method 1) for six of the LLINs reported in Fig. 2 were compared with corresponding, separately reported PHI data for the same brands of net retrieved from the field after 1-3 years in use from the Wheldrake et al. study [13]. The results are shown in Fig. 3 and reveal an association between RD values obtained in the laboratory with PHI field data $\left(\mathrm{r}^{2}=0.78, \mathrm{p}<0.05\right)$.

In relation to $\mathrm{RD}$ values calculated in accordance with Method 2 (Proximity to Aspirational Value by KPI), the same aspirational values were used as in Method 1 as defined in Table 7. The resulting RD values for each LLIN using Method 2 are given in Fig. 4. Generally, the resulting rank order of the RD values were very similar to those determined by Method 1 with six LLIN products achieving $\mathrm{RD}$ values $\geq 50 \%$ and none with $\mathrm{RD}<20 \%$.
As for Method 1, the results for six different branded LLINs retrieved from the field followed the same trend of reducing PHI with increasing RD using Method 2, see Fig. $5\left(r^{2}=0.80, p<0.05\right)$.

Each method of calculating RD was capable of distinguishing LLINs that were more physically robust and capable of resisting damage than others and good correlation was observed between the outputs of both methods, Fig. $6\left(r^{2}=0.96, p<0.05\right)$.

\section{Discussion}

Resisting the major sources of damage LLINs are exposed to during normal use is essential if products are going to remain in good physical condition for many years. For years, the vector control community has relied upon measuring the bursting strength of LLINs in the laboratory to characterize the 'physical strength' of different products. However, these measurements are clearly insufficient given the root causes of hole formation [13]. In practice, there are multiple mechanisms of damage, but representing all in one meaningful resistance to damage (RD) metric would be more reliable. The approach 


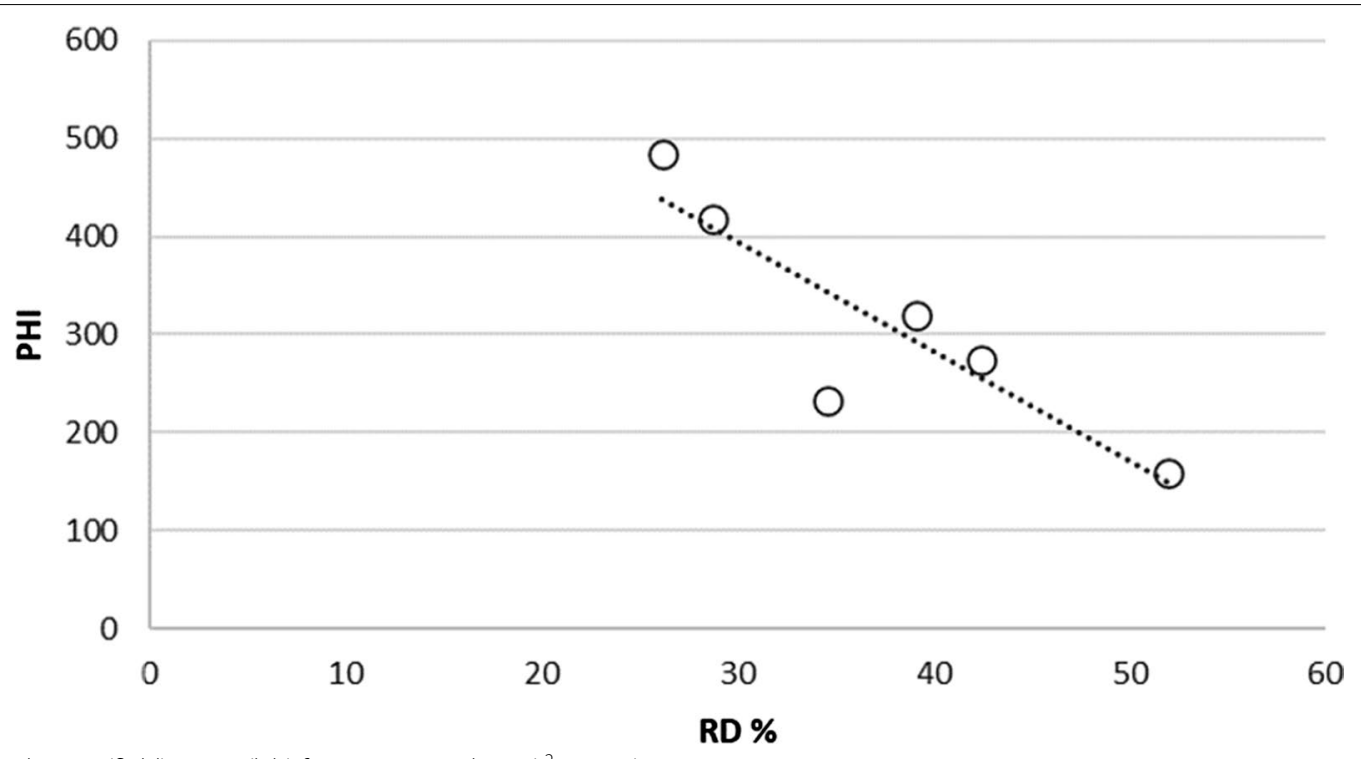

Fig. 3 Method 1: PHI (field) vs. RD (lab) for six LLIN Products $\left(r^{2}=0.78\right)$

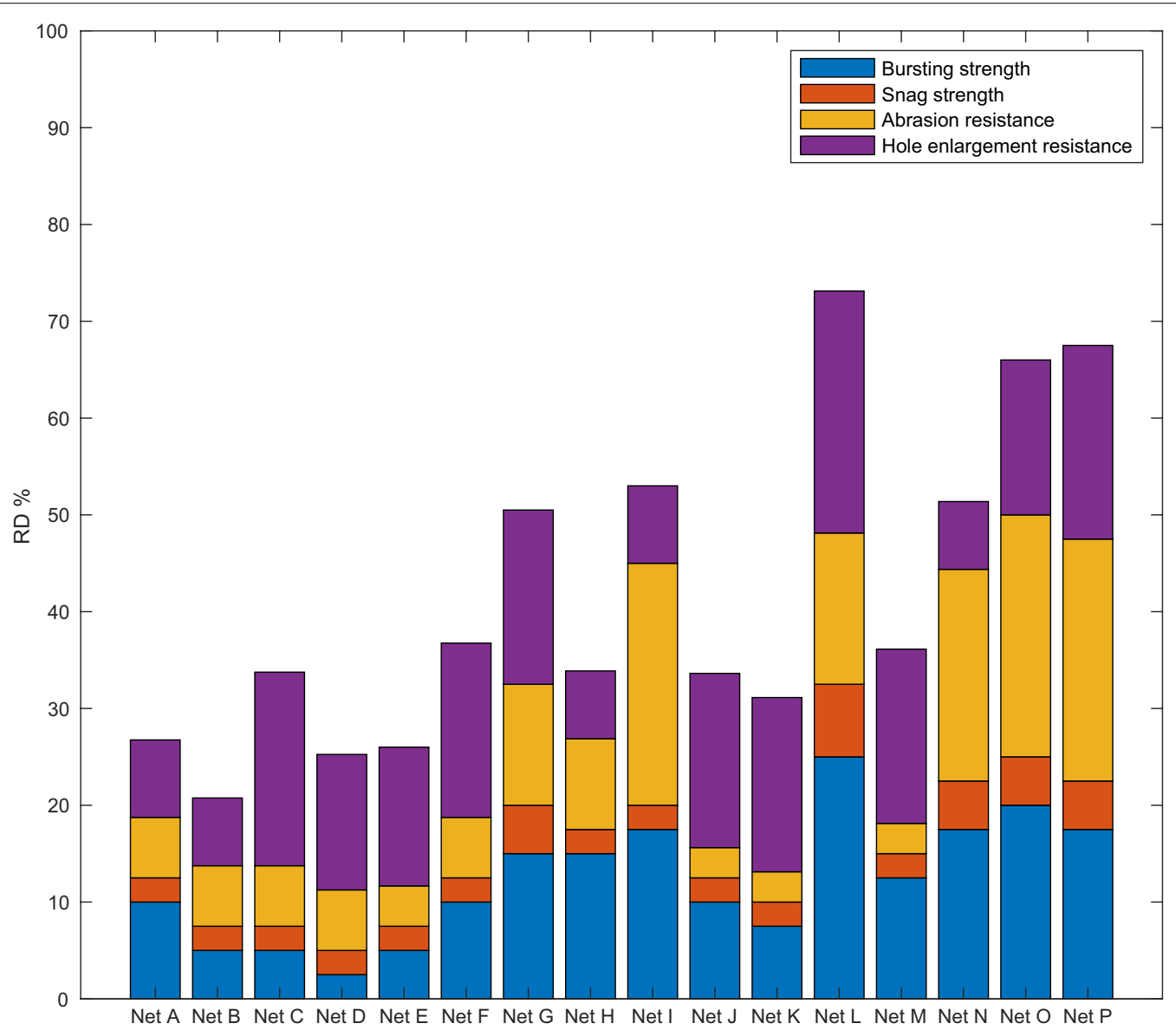

Fig. 4 RD values for all LLINs following algorithm Method 2 


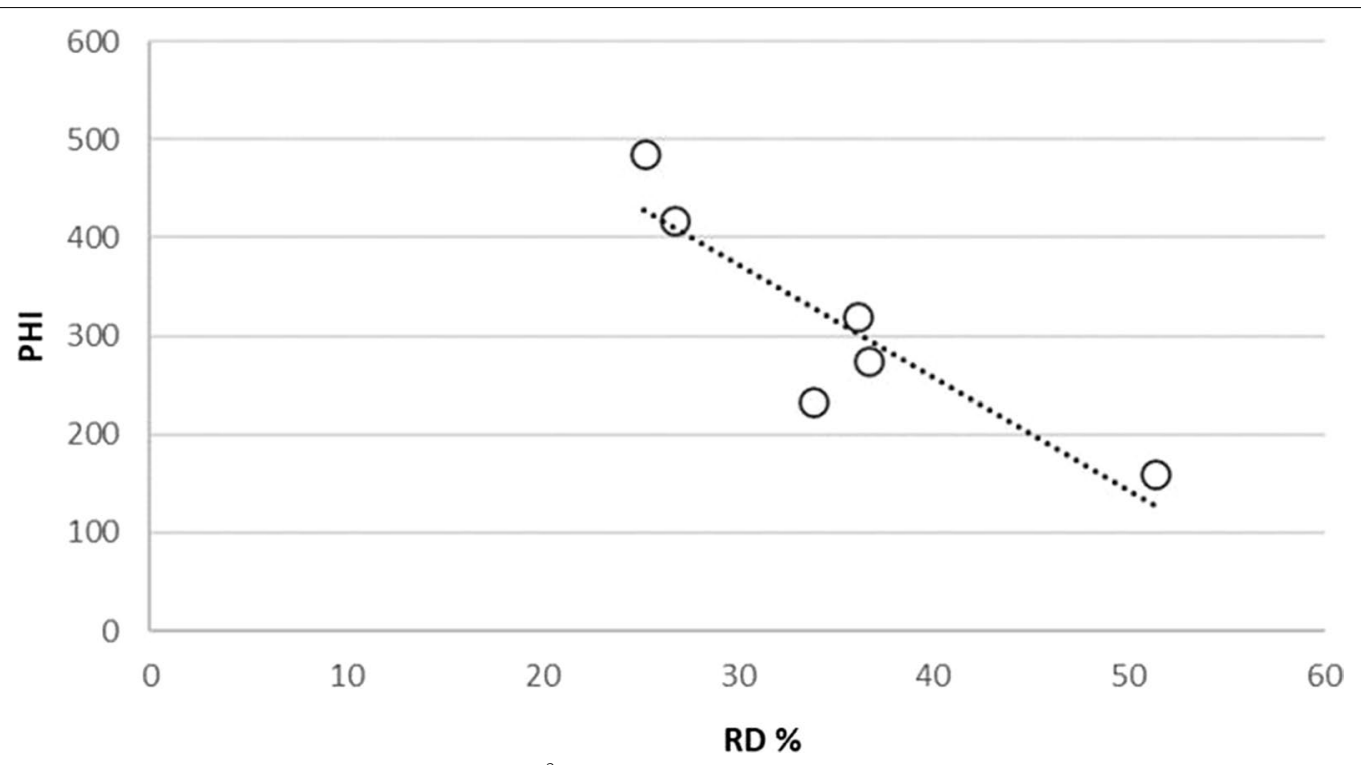

Fig. 5 Method 2: PHI (field) vs. RD (lab) for six LLIN Products $\left(r^{2}=0.80\right)$

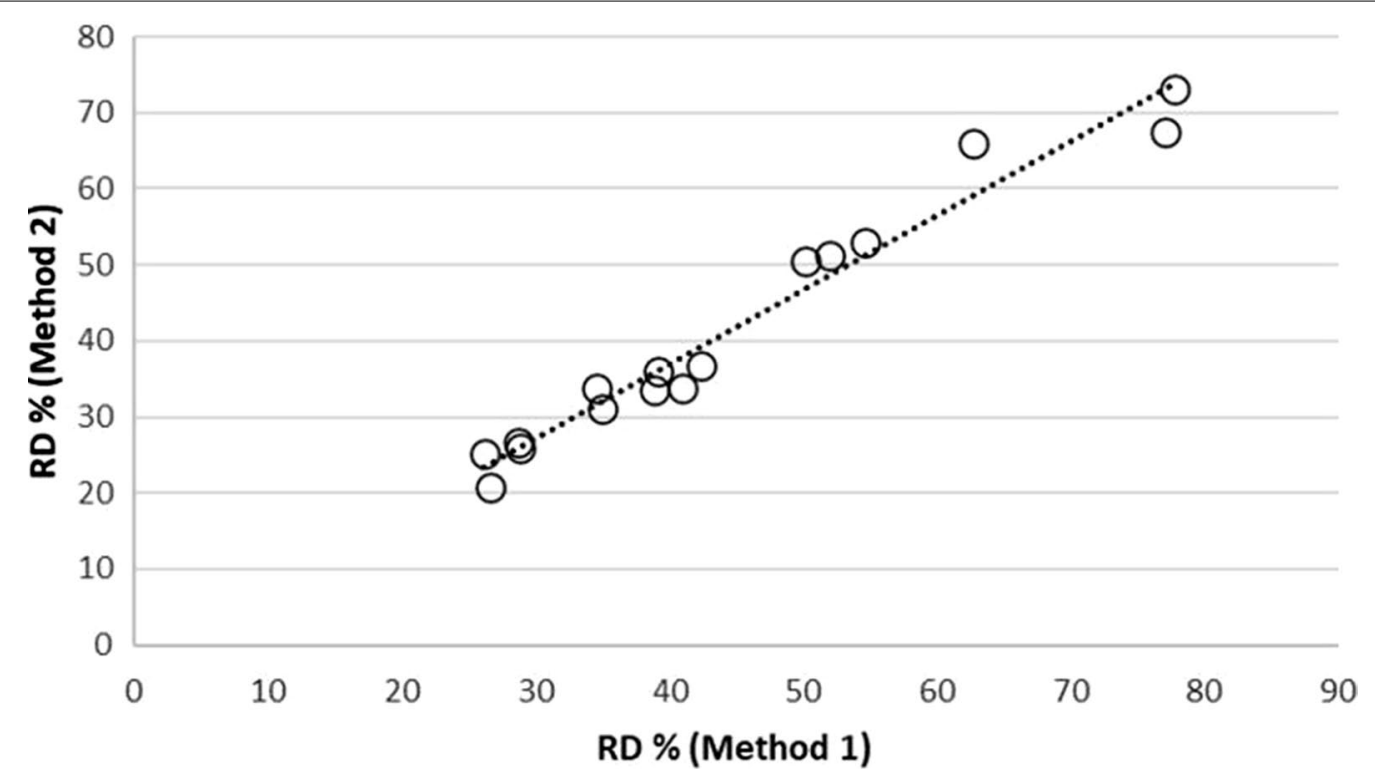

Fig. 6 Correlation of RD values using Method 1 and Method $2\left(r^{2}=0.96\right)$

described in the present work is distinct from other attempts to develop a single composite metric in that no field study evaluations are needed [30], and rapid assessment of any LLIN product is, therefore, possible prior to distribution. The RD approach focuses on measurements conducted under controlled laboratory conditions based on ISO procedures, and has the advantage that the inherent variations in field study evaluations are completely obviated.
In the RD methodology, the concept of aspirational targets has been introduced, taking into account the magnitude of forces LLINs are likely to encounter during normal use. Of course, the setting of these aspirational targets is open to contention, but at the very least, it focuses attention on what is actually needed in terms of functional performance. Based on an analysis of the real forces generated by human adults, a pragmatic approach was adopted for defining upper values for resistance to 
damage in terms of: bursting strength $(700 \mathrm{kPa})$, snag strength $(200 \mathrm{~N})$, abrasion resistance (400 rubs) and hole enlargement (residual hole size $<5 \mathrm{~mm}$ corresponding to a score of 100 without laddering, unravelling or tearing). Note that the setting of aspirational targets needs to be considered not just in terms of product performance, but also in terms of economics. Generally speaking, engineering of LLINs capable of meeting high aspirational values are likely to improve cost effectiveness if LLINs are more robust for the entire life span.

The RD methodology also accounts for the fact that LLINs could be engineered to exceed aspirational targets in the future. Already, warp knitted nets are manufactured for use in other industries that would meet the targets suggested herein, albeit at significantly higher cost. For example, in sportswear applications, warp knitted fabrics with bursting strength values of $>2000 \mathrm{kPa}$ are produced, albeit at heavier basis weights $\left(>90 \mathrm{~g} / \mathrm{m}^{2}\right)$ [31]. In Method 1, the actual proportion of the aspirational target is calculated, such that it is possible to score greater than 100 on the RD scale. This is clearly positive in terms of promoting product innovation. By contrast, in Method 2 the RD value is assigned based on a score matrix. The overall RD value is determined based on tiering of the individual parameter values in equal proportions. In this method it is possible for LLINs with snag strengths of e.g. $40 \mathrm{~N}$ to score the same as a net with snag strength of $59 \mathrm{~N}$; similarly, this is possible with bursting strength and abrasion resistance. Therefore, this method does not enable scoring past $\mathrm{RD}=100 \%$. It is suggested that Method 1 is employed for future characterization of LLIN's physical integrity. One could argue that Method 2 might encourage manufacturers to focus on meeting bare minimum testing requirements, rather than targeting higher performance.

The RD results calculated by both Method 1 and Method 2 demonstrate the scope for improvement in the design of LLIN products. In particular, focus is required to improve snag strength (red, Figs. 2 and 4), which is also the most common form of damage observed in the retrieved field nets [13]. Also, even in LLINs that are considered to be 'strong' in terms of their bursting strength, careful attention should be paid to resisting hole enlargement by unravelling or laddering of the fabric structure.

Assuming normal household use of a LLIN, that avoids interaction with rodents and exposure to naked flames, cigarettes, cooking embers or deliberate cutting with a knife, good correlation between PHI values in the field and calculated RD values from the lab has been observed, for both RD Methods 1 and 2. This supports the assertion that LLINs can be improved to better withstand certain types of common and reasonable mechanical damage, and this is unlikely to be resolved without upgrading product specifications. However, progressive improvements in RD scores, combined with behavioural change aimed at taking care of the product, is likely to have a major impact on long-term physical integrity and survivorship [32]. Although the physical integrity of the nets vary by location, a study carried out by Wheldrake et al. [13] showed that mechanical damage was the main contributor to hole formation across a range of geographies. Therefore, increases in the RD could improve the lifespan of LLINs across the board. Further field comparisons of RD scores and actual physical integrity are now needed to verify the suggested RD methodology as a valid approach to assess expected field performance of specific LLIN brands.

\section{Conclusions}

The Resistance to Damage (RD) metric provides a reliable metric to characterize the physical robustness of LLINs prior to use based on simple laboratory testing of the textile material. Marked differences in RD scores between LLIN products were revealed, but none achieved the aspirational targets to maximize performance in use. Comparison of RD scores with PHI values from the field for the same LLIN brands suggests that higher RD (measured in the lab) is associated with reduced hole formation (in the field). There is significant scope for product innovation aimed at moving much closer to aspirational RD targets and improving relevant performance parameters.

\section{Abbreviations}

WHO: World Health Organization; WHOPES: World Health Organization Pesticide Evaluation Scheme; PHI: Proportionate hole index; ITN: Insecticide-treated net; LLIN: Long-lasting insecticidal net.

\section{Acknowledgements}

The authors acknowledge the contribution of Bill \& Melinda Gates Foundation for the financial support. This study summarizes the findings and recommendations from a two-phase study undertaken by Nonwovens Innovation and Research Institute (NIRI), Tropical Health LLP (led by Albert Kilian), and Results for Development Institute (R4D).

\section{Authors' contributions}

AW and SJR developed the methodology and contributed to the data analysis and preparation of the manuscript. EG contributed to the data analysis and preparation of the manuscript; $\mathrm{VC}$ contributed to the data analysis and to the final manuscript. AK contributed to the data analysis and the preparation of the manuscript. All authors read and approved the final manuscript.

\section{Competing interests}

The authors declare that they have no competing interests.

\section{Author details}

${ }^{1}$ Nonwovens Innovation \& Research Institute Ltd, 169 Meanwood Road, Leeds LS7 1SR, West Yorkshire, UK. ${ }^{2}$ Tropical Health LLP, Montagut, Spain.

Received: 11 September 2020 Accepted: 22 December 2020

Published online: 19 January 2021 


\section{References}

1. WHO. Long-lasting insecticidal nets for malaria prevention-A Manual for Malaria Programme Managers. Trial Edn. Geneva, World Health Organization. 2007. http://www.who.int/management/programme/LongLastin glnsecticidalNetsMalaria.pdf.

2. Kachur SP, Phillips-Howard PA, Odhacha AM, Ruebush TK, Oloo JA, Nahlen BL. Maintenance and sustained use of insecticide-treated bednets and curtains three years after a controlled trial in western Kenya. Trop Med Int Health. 1999:4:728-35.

3. Snow RW, McCabe EM, Mbogo CN, Molyneux CS, Mung'ala VO, Nevill CG. The effect of delivery mechanisms on the uptake of bed net re-impregnation in Kilifi District. Health Policy Plan. 1999;14:18-25.

4. Erlanger T, Enayati AA, Hemingway J, Mshinda H, Tami A, Lengeler C. Field issues related to effectiveness of insecticide-treated nets in Tanzania. Med Vet Entomol. 2004;18:153.

5. Kilian A, Byamukama W, Pigeon O, Atieli F, Duchon S, Phan C. Long-term field performance of a polyester-based long-lasting insecticidal mosquito net in rural Uganda. Malar J. 2008;7:49.

6. Kilian A, Byamukama W, Pigeon O, Gimnig J, Atieli F, Koekemoer L, et al. Evidence for a useful life of more than three years for a polyester-based long-lasting insecticidal mosquito net in Western Uganda. Malar J. 2011;10:299.

7. Haji KA, Khatib BO, Obi E, Dimoso K, Koenker H, Babalola S, et al. Monitoring the durability of the long-lasting insecticidal nets Olyset ${ }^{\circledR}$ and PermaNet ${ }^{\circledR} 2.0$ in similar use environments in Zanzibar. Malar J. 2020;19:187.

8. Lorenz LM, Overgaard HJ, Massue DJ, Mageni ZD, Bradley J, Moore JD, et al. Investigating mosquito net durability for malaria control in Tanzaniaattrition, bioefficacy, chemistry, degradation and insecticide resistance (ABCDR): Study protocol. BMC Public Health. 2014;14:1266.

9. Käse SK, Russell SJ. Modes of hole formation in long-lasting insecticidal nets (LLINs) retrieved from South Eastern Ghana. Parasit Vectors. 2014;7:547.

10. Tan KR, Coleman J, Smith B, Hamainza B, Katebe-Sakala C, Kean C, et al. A longitudinal study of the durability of long-lasting insecticidal nets in Zambia. Malar J. 2016;15:106.

11. Van Roey K, Sovannaroth S, Sochantha T, Srey Touch M, Pigeon O, Sluydts $V$, et al. A phase III trial to evaluate the efficacy, fabric integrity and community acceptance of Netprotect ( $R$ ) using a recommended long-lasting insecticidal net as positive control. Malar J. 2014;13:256

12. Wheldrake A, Guillemois E, Arouni H, Chetty V, Russell SJ. Textile testing to assess the resistance to damage of long-lasting insecticidal nets for malaria control and prevention. Malar J. 2020. https://doi.org/10.1186/ s12936-020-03571-4.

13. Wheldrake A, Guillemois E, Arouni H, Chetty V, Russell SJ. The causes of holes and loss of physical integrity in long-lasting insecticidal nets. Malar J. 2020. https://doi.org/10.1186/s12936-020-03567-0.

14. WHO. Specifications and Evaluations for Public Health Pesticides Deltamethrin Long-Lasting (Coated Onto Filaments) Insecticidal Net. 2015:1-58.

15. BS EN 1005. Safety of machinery - Human physical performance — Part 3: Recommended force limits for machinery operation. 2008.

16. Roymech. Human Strength / Endurance Notes. (2013). Available from https://roymech.org/Useful_Tables/Human/Human_sizes.html. (Accessed 10 Apr 2020)
17. Department of Trade and Industry. Strength data for design safety phase 2. Gov Consum Saf Res. 2002;1:77.

18. Telegraph. The world's fattest countries. How do you compare? (2012). Available from https://www.telegraph.co.uk/news/earth/earth news/9345086/The-worlds-fattest-countries-how-do-you-compa re.html\#: :text=The pacific island nations of,167.1 pounds (75.8 k. (accessed 08 Jun 2020). https://www.telegraph.co.uk/news/earth/earth news/9345086/The-worlds-fattest-countries-how-do-you-compare. html\#: :text=The pacific island nations of,167.1 pounds (75.8 kg).

19. Smith LE, Royce J. Muscular strength in relation to body composition. Ann N Y Acad Sci. 1963;110:809-13.

20. Martin J, Ryntz R, Chin J, Dickie R. Service life prediction of polymeric materials: global perspectives. Springer, 2009. doi:https://doi. org/10.1007/978-0-387-84876-1.

21. Sharma NK. Predicting and reducing warranty costs by considering customer expectation and product performance. Doctoral Dissertation 2239 Missouri S\&T, 2008.

22. Bijen J. Durability of engineering structures. Cambridge: Woodhead Publishing; 2003.

23. Wireman T. Developing Performance Indicators for Managing Maintenance. Industrial Press; 2005. https://books.google.co.uk/books ?id=qSTOnEwyraUC.

24. Parmenter D. Key Performance Indicators (KPI): developing, implementing and using winning KPI's. 2nd Edn. New Jersey: Wiley; 2010.

25. WHO. Guidelines for monitoring the durability of long-lasting insecticidal mosquito nets under operational conditions. Geneva, World Health Organization, WHO/HTM/NTD/WHOPES/2011.5 http://whqlibdoc.who. int/publications/2011/9789241501705_eng.pdf.

26. Smith SC, Ballard JPWT. Development of laboratory tests for the physical durability of long-lasting insecticidal nets (LLINs). 61st Annual Meeting American Society Tropical Medicine Hygiene, Atlanta, 2012. (Abstract 913).

27. WHO. Determination of fabric strength of long-lasting insecticidal nets: report of a WHO consultation, Geneva, World Health Organization, 2015

28. Jerkovic I, Pallares JM, Capdevila X. Study of the abrasion resistance in the upholstery of automobile seats. Autex Res J. 2010;10:14-20.

29. WHO, WHOPES. guidelines for Laboratory and Field-Testing of LongLasting Insecticidal Nets. Geneva: World Health Organization; 2013.

30. Vanden Eng JL, Chan A, Abílio AP, Wolkon A, Ponce de Leon G, Gimnig J, et al. Bed net durability assessments: exploring a composite measure of net damage. PLoS One. 2015;10:e0128499.

31. El-Hady RAM, El-Baky RAA. Performance characteristics of warp knitted lining fabrics used for sportswear. Life Sci J. 2015;12:98-104.

32. Kilian A, Obi E, Mansiangi P, Abílio AP, Haji KA, Guillemois E, et al. Correlation of textile 'resistance to damage' scores with actual physical survival of long-lasting insecticidal nets in the field. Malar J. 2020.

\section{Publisher's Note}

Springer Nature remains neutral with regard to jurisdictional claims in published maps and institutional affiliations.

Ready to submit your research? Choose BMC and benefit from

- fast, convenient online submission

- thorough peer review by experienced researchers in your field

- rapid publication on acceptance

- support for research data, including large and complex data types

- gold Open Access which fosters wider collaboration and increased citations

- maximum visibility for your research: over 100M website views per year

At BMC, research is always in progress.

Learn more biomedcentral.com/submissions 